\title{
EPIDEMIOLOGY OF DIARRHOEA CAUSED BY ENTEROTOXIGENIC CLOSTRIDIUM PERFRINGENS
}

\author{
S. P. Borriello, Fiona E. Barclay, A. R. Welch, M. F. Stringer*, \\ G. N. Watson*, R. K. T. Williams $\dagger$, D. V. Seal $\dagger$, And \\ Kate Sullens ${ }^{\dagger}$
}

Division of Communicable Diseases, Clinical Research Centre, Harrow, ${ }^{*}$ Food Hygiene Laboratory, Central Public Health Laboratory, Colindale, London, NW9 and $\dagger$ Departments of Geriatrics and Microbiology, Northwick Park Hospital, Harrow, Middlesex

\begin{abstract}
SUMmaRY. Enterotoxigenic strains of Clostridium perfringens have recently been implicated in some cases of antibiotic-associated diarrhoea. We present here the results of an epidemiological study of this disease. Five cases of diarrhoea caused by $C$. perfringens serotype 41 occurred during a 9-week period, and then during a 6-week period there were three cases due to serotype 27 and two due to serotype 24; in all but one case two geriatric wards were involved. In total there were 16 cases in 22 months. All cases were identified by the detection of $C$. perfringens enterotoxin in the faeces. The mean number of $C$. perfringens in these cases was $10^{8.8} \mathrm{cfu} / \mathrm{g}$ of faeces. Of 37 patients who had negative test results for $C$. perfringens enterotoxin, 18 had positive cultures for $C$. perfringens, with mean faecal counts of $10^{5.3} \mathrm{cfu} / \mathrm{g}$, and nine of these patients had diarrhoea. Thirteen different serotypes were isolated from these 18 patients, including type 41 from seven patients and type 27 from one. Hand carriage of the offending serotype was demonstrated in three of four infected patients, none of four controls and two of 14 ward staff. $C$. perfringens of serotypes causing disease was isolated from $59 \%$ of environmental areas where there was active disease, $27 \%$ of areas where there had been disease which had since resolved and $9 \%$ of areas where there was no history of disease. The findings imply that cross infection may occur.
\end{abstract}

\section{INTRODUCTION}

Diarrhoea is a frequent side effect of antibiotic therapy and it has been shown during the last 5 years that Clostridium difficile is responsible for nearly all cases of the severe form of this disease, pseudomembranous colitis. On the other hand, $C$. difficile is found much less frequently in cases of diarrhoea or colitis without pseudomembranes (Larson et al., 1984) and many of these are of unknown aetiology. It was recently

Received 30 Oct. 1994; revised version accepted 5 Mar. 1985.

Address for correspondence and reprints: Dr S. P. Borriello, Division of Communicable Diseases, Clinical Research Centre, Watford Road, Harrow, Middlesex HA1 3UJ. 
demonstrated that some of these $C$. difficile-negative cases of antibiotic-associated diarrhoea were associated with enterotoxigenic strains of $C$. perfringens, which could be found in numbers up to $10^{9} \mathrm{cfu} / \mathrm{g}$ in the faeces (Borriello et al., 1984). Additionally, a toxin that was neutralised by antiserum to $C$. perfringens enterotoxin was also present. All the cases so far described have been sporadic, and it has not been possible to determine whether antibiotics allow infection by enterotoxigenic $C$. perfringens acquired from the environment, or allow overgrowth of small numbers normally resident in the gut as commensals. We describe here an epidemiological investigation of a recent outbreak of diarrhoea associated with enterotoxigenic strains of $C$. perfringens, which suggests that the organism may behave as a true infectious agent, in a similar manner to $C$. difficile.

\section{MATERIALS AND METHODS}

Source of specimens. Faecal specimens from all patients with diarrhoea were received undiluted and processed immediately. They were examined for the presence of cytotoxins; and all cytotoxin-positive samples were cultured for $C$. difficile and $C$. perfringens. During the 'outbreak period', when several cases of $C$. perfringens enterotoxin-associated diarrhoea occurred, faecal specimens from patients on the two wards involved were examined for the presence of $C$. perfringens and its enterotoxin irrespective of recent antibiotic therapy or diarrhoea.

Isolation of C. difficile from faeces. A portion of each stool sample was plated directly on to a selective medium for $C$. difficile described in detail elsewhere (Borriello and Honour, 1981), modified by the addition of sodium taurocholate $1 \% \mathrm{w} / \mathrm{v}$, which has been shown to enhance recovery of $C$. difficile (Wilson et al., 1982).

Isolation of C. perfringens from faeces. For selection of clostridial spores, $0 \cdot 5-\mathrm{ml}$ amounts of unformed stool samples, or of a 10-fold dilution of formed stools in Brain Heart Infusion Broth (Difco) (BHI), were added to equal volumes of absolute ethanol (Koransky et al., 1978) and the mixture allowed to stand at room temperature for $1 \mathrm{~h}$, after which serial tenfold dilutions were prepared in BHI. From each dilution, $0 \cdot 1-\mathrm{ml}$ amounts were seeded on to an egg-yolk base medium (EYM) prepared by the addition of the following materials to $1 \mathrm{~L}$ of distilled water: Brain-Heart Infusion (Difco) $37 \mathrm{~g}$; trypticase (BBL) $5 \mathrm{~g}$ L-cysteine hydrochloride $1 \mathrm{~g}$; lactose $9 \cdot 6$ $\mathrm{g}$; neutral red solution $(1 \% \mathrm{w} / \mathrm{v}) 4 \mathrm{ml}$; sodium formaldehyde sulphoxylate $0.3 \mathrm{~g}$; New Zealand agar $12 \mathrm{~g}$; haemin solution (1 $\mathrm{g}$ dissolved in $5 \mathrm{ml}$ of $\mathrm{N} \mathrm{NaOH}$ and made up to $100 \mathrm{ml}$ with distilled water), $1 \mathrm{ml}$; vitamin $\mathrm{K}_{1}$ solution ( $1 \% \mathrm{w} / \mathrm{v}$ in absolute ethanol), $1 \mathrm{ml}$; and egg-yolk suspension (Oxoid) $20 \mathrm{ml}$.

Isolation of $C$. perfringens from the environment and from the skin. Contact petri-dishes (Gibco Europe Ltd, Scotland) containing EYM with neomycin $100 \mathrm{mg} / \mathrm{L}$ were prepared. These plates could be applied directly to any surface for the isolation of $C$. perfringens. In addition, for difficult surfaces, such as the rotor blades of a sluice, dry sterile plain cotton swabs (Medical Wire and Equipment Company Ltd, Wiltshire) were used. These were placed in an enrichment broth of Robertson's cooked meat medium (RCM) with neomycin $100 \mathrm{mg} / \mathrm{L}$, and incubated for 3 days at $37^{\circ} \mathrm{C}$ before subculture on to EYM. Hand carriage was determined by application of all fingers of each hand to one of two plates of EYM with neomycin.

Incubation and identification of clostridia. All seeded plates were incubated anaerobically at $37^{\circ} \mathrm{C}$ in $\mathrm{CO}_{2} 10 \%, \mathrm{H}_{2} 10 \%, \mathrm{~N}_{2} 80 \%$ for $48 \mathrm{~h}$. After incubation, all $C$. difficile selective agar plates were examined under long wave $(360 \mathrm{~nm})$ ultraviolet light (UV L-25 Mineralight Lamp; Ultraviolet Products Ltd, Cambridge) for the 'green chartreuse' fluorescence characteristic of $C$. difficile colonies (George et al., 1979). At least three of these colonies, when present, were subcultured into RCM. After incubation for 3 days the cultures were checked for purity and identified by the criteria of Holdeman et al. (1977). Presumptive colonies of $C$. perfringens were identified on the EYM on the basis of lecithinase production. Where possible, up to ten colonies present at the highest dilution were subcultured into RCM and, after incubation for 3 days, were checked for purity and confirmed as $C$. perfringens (Holdeman et al., 1977). All isolates of $C$. perfringens were serotyped and representative isolates of each type from patients with $C$. 
perfringens enterotoxin-associated diarrhoea were screened for enterotoxin production in vitro (Stringer et al., 1982) after final growth in the following four media; Duncan-Strong medium (DS) with starch $0.4 \%$; DS with raffinose $0.4 \%$; 'Tsai' medium (T) with starch $0.4 \%$; and T with raffinose $0.4 \%$. Representatives of the serotypes associated with the disease, but isolated either from the environment or from patients who did not have free enterotoxin in their faeces, were also screened for toxin production.

Detection of toxins. Stool specimens were suspended in Hanks's balanced salts solution to approximately $10 \% \mathrm{w} / \mathrm{v}$ and centrifuged at $12000 \mathrm{rpm}$ for $30 \mathrm{~min}$ at $4{ }^{\circ} \mathrm{C}$ in a MSE High Speed 18 centrifuge (MSE Scientific Instruments, Sussex). The supernate was inoculated into monolayers of young cultures of a continuous line of African green monkey kidney cells (VERO) (Borriello and Welch, 1984). Cultures were examined after 24 and $48 \mathrm{~h}$ for cytopathic effects. Specimens producing changes in the cells were re-inoculated in duplicate after individual mixing with an equal volume of $C$. sordelli anti-toxin (Wellcome Research Laboratories), which neutralises $C$. difficile toxins, and $C$. perfringens anti-enterotoxin prepared as described by Bartholomew and Stringer (1983). The presence of $C$. perfringens enterotoxin was confirmed in most cases by a recently described enzyme immunoassay (Bartholomew and Stringer, 1984) which was also used to detect enterotoxin produced by strains of $C$. perfringens in vitro. The toxigenicity of isolates of C. difficile was determined by adding sterile filtrates $(0.45-\mu \mathrm{m}$ pore size $)$ of 3 day-old cultures in RCM to monolayers of VERO cells (Borriello and Welch, 1984).

\section{RESULTS}

During a 22-month period from October 1982 to June 1984, 761 stool samples from patients with diarrhoea at this hospital were examined for the presence of toxins that were cytotoxic to VERO cells in tissue culture. During the 11-month period from October 1982 to August 1983, 19 of 270 stool samples examined were shown to have a cytotoxin present; in 17 cases $C$. difficile cytotoxin was identified, and in two the cytotoxigenic $C$. perfringens enterotoxin was present (table I). These two were sporadic cases occuring 5 months apart in different areas of the hospital (Outpatients Department and ward IV); one case was due to C.perfringens serotype 36 and the other to serotype TW/51 (table I). However, during a 15-week period from the end of September 1983 to the beginning of January 1984 there were 10 cases of diarrhoea due to enterotoxigenic $C$. perfringens, nine of which occurred on two geriatric wards (table I-wards I and II). Five of these, which occurred during a 9-week period, were associated with enterotoxigenic $C$. perfringens serotype 41 ; four cases occurred on the

TABLE I

Incidence of $C$. perfringens enterotoxin-associated diarrhoea during a 22-month study period compared with that due to $C$. difficile

\begin{tabular}{l|ccccc}
\hline Period & $\begin{array}{c}\text { Number of } \\
\text { faecal samples } \\
\text { tested }\end{array}$ & $\begin{array}{c}\text { Number of } \\
\text { patients with } \\
\text { C. perfringens } \\
\text { enterotoxin }\end{array}$ & $\begin{array}{c}\text { Serotypes of } \\
\text { enterotoxigenic } \\
\text { C. perfringens } \\
\text { strains (number } \\
\text { of patients) }\end{array}$ & $\begin{array}{c}\text { Wards involved with C. difficile } \\
\text { (number of } \\
\text { patients) }\end{array}$ & $\begin{array}{c}\text { Number of } \\
\text { patients } \\
\text { (all wards) }\end{array}$ \\
\hline $\begin{array}{l}\text { Oct. 1982-Aug. 1983 } \\
\text { Sep. 1983-Nov. 1983 }\end{array}$ & 270 & 2 & $36 ;$ TW/51 & OPD. IV & 17 \\
Dec. 1983-Jan. 1984 & 137 & 5 & $41(5)$ & I(4). III(1) & 11 \\
Feb. 1984-Jun. 1984 & 248 & 5 & $24(2) ; 27(3)$ & I(2). II(3) & 2 \\
\hline
\end{tabular}

OPD = outpatient department; I and II = geriatric wards; III = surgical oncology; IV = isolation ward; $\mathrm{V}=$ orthopaedic/rheumatology ward; $\mathrm{VI}=$ mixed general surgery and medicine; $\mathrm{VII}=$ general medicine. 
same ward (ward I). The other five cases clustered during a 6-week period and involved three patients with $C$. perfringens serotype 27 and two with serotype 24 (Table Iwards I and II). The two geriatric wards are 25 -bedded acute wards and were fully occupied during the outbreak period. During the period of diarrhoea associated with C. perfringens serotype 41 , the first of the five affected patients (ward I) excreted the organism and its toxin for 10 days, recovered, but then relapsed 25 days later, excreting $C$. perfringens and enterotoxin for a further 15 days. The other four cases occurred during a period of 16 days, at intervals from the last positive sample from the first patient of 1, 5, 5 and 10 days, respectively. During the same 15-week period, 13 of the 243 faecal specimens examined from all parts of the hospital were positive for $C$. difficile cytotoxin, but there was no temporal or geographical clustering of these $C$. difficile-associated diarrhoea cases. Since February 1984, 248 specimens have been examined, revealing 18 cases of $C$. difficile diarrhoea and only four sporadic cases of $C$. perfringens enterotoxin diarrhoea (table I). Three of the $C$. perfringens-associated cases occurred on three different wards and involved serotype 53 in one case and two nontypable strains in the other two cases (table I). The remaining patient was attending an outpatient clinic and had diarrhoea associated with $C$. perfringens serotype 59.

Of the 16 cases of $C$. perfringens enterotoxin-associated diarrhoea, 11 patients had received antimicrobials within 4 weeks before their symptoms, three had no recent history of antimicrobial treatment and data were unavailable on the other two patients. The antimicrobials associated with the cases were, benzylpencillin (1), amoxycillin (3), flucloxacillin (1), cefuroxime (2), trimethoprim (2), co-trimoxazole (1) and amoxycillin with cephalexin (1).

\section{Background carriage rate of $C$. perfringens}

Stools were collected from patients on the two geriatric wards where all but one of the cases occurred (wards I and II) and were examined for the presence of $C$. perfringens and its associated enterotoxin, irrespective of recent antibiotic therapy or diarrhoea. This screening procedure was conducted during the outbreak period from September 1983 to January 1984. Nine samples were collected during the serotype-41 case cluster; seven of these were from patients on ward I and two from patients on ward II. The ward-I samples consisted of two from patients with diarrhoea of unknown aetiology, one with diarrhoea due to campylobacter and four from patients without diarrhoea. During the $C$. perfringens serotype- 41 cluster of cases, the 25 -bedded ward was fully occupied with $\mathbf{4 1}$ different patients overall. Eighteen of these patients had received antibiotics, which included all four with $C$. perfringens diarrhoea, one of three patients with diarrhoea due to other causes and 13 patients without diarrhoea.

Twenty-one samples were collected at the end of this period and before the second cluster of cases, 15 during the second cluster of cases and three immediately after this period. In total, there were 48 specimens from 37 patients where there was no detectable $C$. perfringens enterotoxin (table III), although some of them did have diarrhoea (table II) and some carried $C$. perfringens serotype 41 or 27 (table II). Only $50 \%$ of these patients had received antibiotics, in contrast to $79 \%$ of the 14 patients with enterotoxin-positive stools for whom an antibiotic history could be obtained. Nine of the 23 patients with diarrhoea who did not have detectable $C$. perfringens enterotoxin in the stools had $C$. perfringens present at a mean concentration of $10^{5.4} \mathrm{cfu} / \mathrm{g}$ of stool 
TABLE II

Prevalance of $C$. perfringens among hospitalised patients with negative tests for faecal enterotoxin during the outbreak period

\begin{tabular}{|c|c|c|c|c|c|c|}
\hline \multirow[b]{2}{*}{ Ward } & \multirow{2}{*}{$\begin{array}{l}\text { Sampling period } \\
\text { (months) }\end{array}$} & \multirow{2}{*}{$\begin{array}{l}\text { Number of } \\
\text { specimens } \\
\text { tested }\end{array}$} & \multirow{2}{*}{$\begin{array}{l}\text { Number of } \\
\text { patients } \\
\text { examined }\end{array}$} & \multicolumn{2}{|c|}{ Number of positive results } & \multirow{2}{*}{$\begin{array}{l}\text { Serotypes of } C \text {. perfringens } \\
\text { isolated (number of strains) }\end{array}$} \\
\hline & & & & specimens & patients & \\
\hline I & 3 & 26 & $22(12)^{*}$ & 15 & $12(6)^{*}$ & $\begin{array}{l}\text { NT(8), 41(5), 39, } 28, \\
\text { PS.18, 27/38, 29, } \\
\text { TW.23, 57, 34, 6, } \\
23 .\end{array}$ \\
\hline II & 3 & 22 & $15(11)$ & 10 & $7(3)$ & $\begin{array}{l}\text { NT (4), } 41 \text { (2), } \\
23,27, \text { NSA }\end{array}$ \\
\hline Total & & 48 & $37(23)$ & 25 & $19(9)$ & 12 different typable strains. \\
\hline
\end{tabular}

* Number of patients with diarrhoea.

TABLE III

Comparison of concentrations of $C$. perfringens in faeces from various elderly patient groups

\begin{tabular}{|c|c|c|c|}
\hline Group (Number of patis & & $\begin{array}{l}\text { Number of patients } \\
\text { with } C \text {. perfringens }\end{array}$ & $\begin{array}{l}\text { Mean } \log _{10} \text { cfu of } C \text {. perfringens } / g \\
\text { of stool (range) and median }\end{array}$ \\
\hline $\begin{array}{l}\text { C. perfringens enterotoxin } \\
\text { not detected in the stool } \\
\text { No diarrhoea } \\
\text { Diarrhoea }\end{array}$ & $\begin{array}{l}(37) \\
(14) \\
(23)\end{array}$ & $\begin{array}{r}18 \\
9 \\
9\end{array}$ & $\begin{array}{l}5 \cdot 3(2 \cdot 1-8 \cdot 0) 5 \cdot 5 \\
5 \cdot 1(2 \cdot 1-7 \cdot 4) 6 \cdot 0 \\
5 \cdot 4(2 \cdot 1-8 \cdot 0) \\
5 \cdot 3\end{array}$ \\
\hline $\begin{array}{c}\text { C. perfringens enterotoxin } \\
\text { detected in the stool } \\
\text { No diarrhoea } \\
\text { Diarrhoea }\end{array}$ & $\begin{array}{r}(16) \\
(0) \\
(16)\end{array}$ & $\begin{array}{r}16 \\
0 \\
16\end{array}$ & $\begin{array}{l}8.8(7.5-10.3) 8.9 \\
8.8(7.5-10.3) 8.9\end{array}$ \\
\hline
\end{tabular}

and a range of $10^{2 \cdot 1}-10^{8} \mathrm{cfu} / \mathrm{g}$ (table III). These levels of $C$. perfringens carriage were not dissimilar to those found in the nine patients who had $C$. perfringens but did not have diarrhoea (table III). In neither case was there an association between recent antibiotic administration and carriage of $C$. perfringens. The numbers of $C$. perfringens / $\mathrm{g}$ of stool were lower in the patient group who did not have $C$. perfringens enterotoxin in their stools than in the patient group with $C$. perfringens enterotoxin-associated diarrhoea (table III).

Of the serotypes involved in the two main clusters of cases of $C$. perfringens enterotoxin-associated diarrhoea, serotype 41 was present in seven and serotype 27 in one of the patients who did not have $C$. perfringens enterotoxin in their faeces (table II). Only four of these patients had received antibiotics recently and two of them, both carrying serotype 41, did not have diarrhoea. All 12 of the serotype-41 isolates tested, including those of type 41 from two of the patients who did not have diarrhoed, were enterotoxigenic, whereas the two isolates of serotype 27 were not.

A random selection of five isolates of $C$. perfringens of serotypes unrelated to the outbreak of diarrhoea, from four patients without $C$. perfringens enterotoxin in their stools, were also screened for enterotoxin production in vitro. These strains were serotypes 6, 34 and 57 from two patients without diarrhoea and a non-typable strain and a serotype-39 strain from two patients with diarrhoea. Of the five isolates from 
patients without diarrhoea only the serotype-34 strain produced enterotoxin in vitro. Both the serotype-39 and non-typable strains isolated from patients with diarrhoea were enterotoxigenic.

\section{Hand carriage}

The results of attempted isolations from the fingers of patients and the staff dealing with them are presented in table IV. The serotypes of $C$. perfringens associated with the diarrhoea were present on the hands of three of the four patients investigated; $C$. perfringens was not found on the hands of age matched controls on the same wards. Two members of staff (a physiotherapist and a nurse) of the 14 investigated on ward I, where the serotype 41-associated cluster of cases occurred, had $C$. perfringens serotype 41 present on their hands.

TABLE IV

Hand carriage of $C$. perfringens

\begin{tabular}{l|cccccc}
\hline Group & Number & Ward & $\begin{array}{c}\text { Serotype causing } \\
\text { diarrhoea }\end{array}$ & $\begin{array}{c}\text { Number with } \\
\text { C. perfringens }\end{array}$ & Serotype present \\
\hline $\begin{array}{l}\text { C. perfringens enterotoxin- } \\
\text { associated diarrhoea }\end{array}$ & 3 & I & 41 & 2 & $41(\times 2) ; 16 ;$ NT \\
Age matched controls without & 1 & II & 27 & 1 & 27 \\
C. perfringens diarrhoea & 3 & I & $\ldots$ & 0 & $\ldots$ \\
Staff & 1 & II & $\ldots$ & 0 & $\ldots$ \\
\hline
\end{tabular}

\section{Isolation from inanimate surfaces}

C. perfringens was frequently isolated from surfaces in the hospital (table V). In all cases, whether single patient rooms, general ward areas or sluice rooms were considered, the highest rate of isolation came from those areas where active cases of $C$. perfringens enterotoxin-associated diarrhoea were present, with $65 \%$ of the examined surfaces positive. This figure fell to $45 \%$ for samples taken after this diarrhoea had resolved, and to $30 \%$ for areas with no history of this type of diarrhoea (table V). A similar pattern emerged for the serotypes associated with the diarrhoea, with isolation rates of $59 \%, 27 \%$ and $9 \%$ respectively (table $\mathrm{V}$ ). The degree of contamination, as denoted on a scale of $4+(50$ or more colonies of $C$. perfringens) through to $1+$ (up to 3 colonies of $C$. perfringens), was also greater in those areas where there was active disease and lowest in those areas where there was no history of the disease. The areas from which the 'outbreak' strains of $C$. perfringens were isolated included toilet seats, hand rails, the floor under beds, bed sheets, bed frames, bedside tables, radiators, radios, baths, shelves, sinks and tap handles and chair arm rests. Samples taken from five single rooms where there was no history of $C$. perfringens diarrhoea included one with a patient with $C$. difficile diarrhoea, three with patients who did not have diarrhoea, and an unoccupied room on an isolation ward. The eight areas which were positive for $C$.perfringens came from two occupied rooms, two of these sites were in the room which contained the patient with $C$. difficile diarrhoea. All five sites positive for one of the outbreak strains of $C$. perfringens (serotype 41) were in one of these rooms. It 
TABLE V

Recovery of $C$. perfringens from the ward environment

\begin{tabular}{|c|c|c|c|c|c|c|}
\hline \multirow[b]{3}{*}{ Sites examined } & \multicolumn{6}{|c|}{$\begin{array}{l}\text { Number of sites positive for } C \text {. perfringens serotypes associated with diarrhoea (A) and } \\
\text { for all serotypes of } C \text {. perfringens }(B) / \text { number of sites examined in patients with }\end{array}$} \\
\hline & \multicolumn{2}{|c|}{$\begin{array}{l}\text { active } C \text {. perfringens } \\
\text { diarrhoea }\end{array}$} & \multicolumn{2}{|c|}{$\begin{array}{l}\text { C. perfringens } \\
\text { diarrhoea resolved }\end{array}$} & \multicolumn{2}{|c|}{$\begin{array}{c}\text { no history of } \\
\text { C. perfringens diarrhoea }\end{array}$} \\
\hline & A & B & A & B & A & B \\
\hline $\begin{array}{l}\text { Wards } \\
\text { Single rooms } \\
\text { Sluice rooms }\end{array}$ & $\begin{array}{r}8 / 12 \\
17 / 24 \\
7 / 18\end{array}$ & $\begin{array}{r}8 / 12 \\
19 / 24 \\
8 / 18\end{array}$ & $\begin{array}{c}14 / 43 \\
1 / 9 \\
1 / 8\end{array}$ & $\begin{array}{c}24 / 43 \\
1 / 9 \\
2 / 8\end{array}$ & $\begin{array}{l}1 / 23 \\
5 / 30 \\
0 / 13\end{array}$ & $\begin{array}{l}9 / 23 \\
8 / 30 \\
3 / 13\end{array}$ \\
\hline Total & $32 / 54(59 \%)$ & $35 / 54(65 \%)$ & $16 / 60(27 \%)$ & $27 / 60(45 \%)$ & $6 / 66(9 \%)$ & $20 / 66(30 \%)$ \\
\hline
\end{tabular}

was unfortunate that the faecal carriage of $C$. perfringens in this patient could not be investigated. The only other serotype of $C$. perfringens associated with disease that was isolated from the environment of areas where there was no history of $C$. perfringens diarrhoea was a single isolate of serotype 27 . The serotypes associated with disease were never found in sluice rooms on wards where there was no history of $C$. perfringens diarrhoea.

Representative isolates of serotypes 41 and 27 which were isolated from single rooms, the general ward and sluice-room areas during periods of active $C$. perfringens enterotoxin-associated diarrhoea, and during periods when the diarrhoea had resolved, and from similar areas where there had been no history of this type of diarrhoea, were screened for production of enterotoxin in vitro. Eight of the 12 isolates tested were shown to be enterotoxigenic. This total consisted of four out of eight serotype-41 isolates and all four serotype- 27 isolates tested. The two isolates of serotype 41 which were isolated from surfaces in a single room on a ward where there was no known history of diarrhoea due to this organism failed to produce enterotoxin in vitro.

\section{Discussion}

Enterotoxigenic strains of $C$. perfringens have long been known to cause food poisoning (Stringer et al., 1980) but it was not until recently that a possible role in antibiotic-associated or sporadic diarrhoea unrelated to food poisoning was demonstrated (Borriello et al., 1984). All but one of the patients described in the previous work had been on antibiotics, in particular the penicillins; however, as most of the patients were elderly and were in hospital, this association with antibiotics may have been coincidental. It is, therefore, of interest that in this study all but three of the patients with diarrhoea due to enterotoxigenic strains of $C$. perfringens for whom there was an antibiotic history had received antibiotics within 4 weeks of the start of their diarrhoea, whereas only half of the control patients who did not have this disease had received antibiotics. It would appear that there is a good association between recent exposure to antibiotics and risk of infection and disease due to this organism. It is probable, in the majority of cases not associated with food poisoning, that antibiotics disrupt the normal flora of the gastro-intestinal tract sufficiently to allow small numbers of these strains of $C$. perfringens to flourish and produce enterotoxin. An important 
point to consider is the question of whether the causative organism is normally resident in small numbers and overgrows under favourable conditions producing disease, or behaves as a true infectious agent colonising susceptible people de novo. The clustering of cases noted in this study, which were associated with a limited number of enterotoxigenic serotypes of $C$.perfringens, and the isolation of the causative organism from the environment and hands of patients with the disease implies that it is a true infection and that there is ample opportunity for cross-infection to occur. In support of this view is the fact that the disease was resolved by nursing the affected patients as a cohort and implementing strict cross-infection control measures (Williams et al., in press). It is also of interest that the serotypes associated with the disease were rarely found in patients without diarrhoea or in patients with diarrhoea which did not appear to be caused by $C$. perfringens enterotoxin. This finding excludes the possibility that the incriminated serotypes were the dominant $C$. perfringens component of the faecal flora amongst the elderly patients in this hospital. No dominant type of $C$. perfringens was found in the group with faeces that were negative for enterotoxin. In fact, only $50 \%$ of this group carried $C$. perfringens when tested and a large variety of different serotypes was present in these patients. This contrasts with the findings of others who have shown a high carriage rate of $C$. perfringens amongst hospitalised or institutionalised aged adults and that a common serotype may emerge (Yamagishi et al., 1976; Stringer, 1981). It has also been shown that multiple serotypes of $C$. perfringens may be isolated from the faeces and rectal mucosa of patients and that the types recovered may vary over short periods of time (Borriello, 1981). So, although the serotypes of $C$. perfringens associated with the disease were rarely found in the comparison group, it is impossible to exclude the possibility that they were present transiently in small numbers in those patients.

It is difficult to explain the presence of the enterotoxigenic serotypes that were associated with the disease in patients who did not have diarrhoea, or in those with diarrhoea but in whom enterotoxin could not be detected. In both cases, it is possible that the strains failed to produce enterotoxin in vivo, or that enteroxin produced was neutralised by the host. In one case it was shown that the strain carried was a nonenterotoxigenic variant. Strains may gain or lose their enterotoxigenicity, although the means by which this is achieved are little understood (Duncan et al., 1972). In those patients with diarrhoea but no detectable levels of enterotoxin, we cannot rule out the possibility that some of these strains were the cause of the illness; it is possible that levels of enterotoxin sufficient to cause disease were produced but that insufficient amounts of the toxin remained in the faeces to be detected. It is of interest that serotypes of $C$. perfringens, other than those associated with the cluster of stool enterotoxin-positive cases, appeared to be more readily capable of producing enterotoxin in vitro when isolated from patients with diarrhoea than when isolated from patients without diarrhoea. Therefore, diarrhoea in these cases could also have been due to undetectable levels of enterotoxin.

In all of the above cases, only faecal carriage of $C$. perfringens was investigated. It is probable that toxin production and resulting diarrhoea depends upon colonisation of the small bowel and that the asymptomatic carriage of enterotoxigenic strains of $C$. perfringens observed in this and other studies (Uemura, 1978) is a reflection of lack of colonisation at this site. In support of this view is the fact that although $C$. perfringens enterotoxin will induce secretion in the small bowel of experimental animals it will not 
do so in the ligated rabbit caecum (McDonel and Demers, 1982). This may help to explain the successful treatment of $C$. perfringens enterotoxin-associated diarrhoea with metronidazole, and the concomitant disappearance of enterotoxin from the faeces despite the persistence in the faeces of relatively large numbers of the enterotoxigenic strains of $C$. perfringens causing the disease (Borriello and Williams, 1985). It is possible that successful treatment with metronidazole is due to eradication of the organism from the small bowel.

Although it is known that $C$. perfringens can be isolated from dust and air in hospitals (Lowbury and Lilly, 1958, Noble et al., 1963), we were surprised at the range of static surfaces and objects that could serve as fomites and the degree of contamination noted in these areas. It is obvious that this level of contamination, especially that associated with commonly handled objects such as radios, could readily cause cross-infection among susceptible patients. The fact that the serotypes of $C$. perfringens associated with the disease in these patients were isolated much less frequently from the environment once the diarrhoea had resolved implies that continual re-seeding of the environment is necessary to maintain the high degree of contamination.

Apart from the spread of the organism by hand carriage and fomites, and the possibility of airborne transmission, it is important to note that mops and the water in mop buckets were also found to be contaminated with the offending serotypes of $C$. perfringens. This would obviously be an efficient method of spreading the organism throughout a hospital ward. Although these factors could have contributed to the rare finding of the serotypes associated with the disease in areas where there was no history of the disease, this is doubtful in the case of the serotype- 41 isolates because they were all found in one single room. It is much more likely that these organisms, which surprisingly were non-enterotoxigenic in vitro, were seeded into the environment by a previous occupant.

Cases of $C$. perfringens enterotoxin-associated diarrhoea in this study were not as common as those due to $C$. difficile, and although $C$. perfringens is thought to be the cause of only about $2 \%$ of antibiotic-associated diarrhoea (Borriello et al., 1984) it is evident that it can also be associated with diarrhoea unrelated to either antibiotics or food poisoning. Most of our 16 cases were elderly patients, a group among whom diarrhoea is a common problem. The discovery of $C$. perfringens as a cause of diarrhoea in this age group may help to explain a number of these cases. The evidence presented implies that enterotoxigenic $C$. perfringens may behave as a true infectious agent, probably in much the same way as $C$. difficile, and that the implementation of cross-infection control measures may be prudent when dealing with cases of this disease.

\section{REFERENCES}

Bartholomew B A, Stringer M F 1983 Observations on the purification of Clostridium perfringens type A enterotoxin and the production of specific antiserum. FEMS Microbiology Letters 18:43-48.

Bartholomew B A, Stringer M F 1984 Clostridium perfringens enterotoxin: a brief review. Biochemical Society Transactions 12: 195-197.

Borriello S P 1981 Clostridial flora of the gastrointestinal tract in health and disease. PhD thesis, University of London.

Borriello S P, Honour P 1981 Simplified procedure for the routine isolation of Clostridium difficile from faeces. Journal of Clinical Pathology 34: 1124-1127. 
Borriello S P, Larson H E, Welch A R, Barclay F, Stringer M F, Bartholomew B A 1984 Enterotoxigenic Clostridium perfringens: A possible cause of antiobiotic-associated diarrhoea. Lancet 1:305-307.

Borriello S P, Welch A R 1984 Detection of Clostridium difficile toxins. In: Borriello S P (ed) Antibiotic-associated diarrhoea and colitis. Martinus Nijhoff, Boston, MA, pp 49-56.

Borriello S P, Williams R K T 1985 Treatment of Clostridium perfringens enterotoxin-associated diarrhoea with metronidazole. Journal of Infection 10:65-67.

Duncan C L, Strong D H, Sebald M 1972 Sporulation and enterotoxin production by mutants of Clostridium perfringens. Journal of Bacteriology 110:378-391.

George W L, Sutter V L, Citron D, Finegold S M 1979 Selective and differential medium for isolation of Clostridium difficile. Journal of Clinical Microbiology 9:214-219.

Holdeman L V, Cato E P, Moore W E C 1977 Anaerobe laboratory manual, 4th edn. Virginia Polytechnic Institute, Blacksburg, VA.

Koransky J R, Allen S D, Dowell V R 1978 Use of ethanol for selective isolation of spore forming micro-organisms. Applied and Environmental Microbiology 35: 762-765.

Larson H E, Borriello S P, Honour P, Welch A R 1984 Clostridium difficile and its toxin in human disease. In: Jeljaszewicz J. Alouf J (eds) Bacterial protein toxins, Academic Press, London, pp 339, 345.

Lowbury E J L, Lilly H A 1958 The sources of hospital infection of wounds with Clostridium welchii. Journal of Hygiene 56:169-182.

McDonel J L, Demers G W 1982 In vivo effects of enterotoxin from Clostridium perfringens Type A in the rabbit colon: Binding vs. biologic activity. Journal of Infectious Diseases 145:490494.

Noble W C, Lidwell O M, Kingston D 1963 The size distribution of airborne particles carrying micro-organisms. Journal of Hygiene 61:385-391.

Stringer M F 1981 Studies on Clostridium perfringens food poisoning. $\mathrm{PhD}$ thesis, University of London.

Stringer M F, Turnbull P C B, Gilbert R J 1980 Application of serological typing to the investigation of outbreaks of Clostridium perfringens food poisoning, 1970-1978. Journal of Hygiene 84:443-456.

Stringer M F, Watson G N, Gilbert R J 1982 Clostridium perfringens type A: serological typing and methods for the detection of enterotoxin. In: Corry J E L, Roberts D, Skinner F A (eds) Isolation and identification methods for food poisoning organisms. Academic Press, London, pp 111-135.

Uemura T 1978 Incidence of enterotoxigenic Clostridium perfringens in healthy humans in relation to the enhancement of enterotoxin production by heat treatment. Journal of Applied Bacteriology 44:411-419.

Williams R et al. Diarrhoea due to exterotoxigenic Clostridium perfringens: Clinical features and management of a cluster of cases. Age and Ageing (in press).

Wilson K H, Kennedy M J, Fekety F R 1982 Use of sodium taurocholate to enhance spore recovery on a medium selective for Clostridium difficile. Journal of Clinical Microbiology 15: 443-446.

Yamagishi T, Serikawa T, Morita R, Nakamura S, Nishida S 1976 Persistent high numbers of Clostridium perfringens in the intestines of Japanese aged adults. Japanese Journal of Microbiology 20:397-403. 